\title{
DERMATOGLYPHIC PATTERNS IN TYPE 2 DIABETES MELLITUS
}

\section{Sehmi S}

Correspondence to professor, Department of Anatomy, Sri Guru Ram Das Institute of Medical Sciences and Research, Vallah E 444,445 Ranjit Avenue Amritsar. drseema16@gmail.com

\begin{abstract}
Dermatoglyphics is the study of epidermal ridge patterns on the palm, fingers, sole and toes. They are genetically determined and are useful in diagnosis of various genetic diseases like Diabetes mellitus. There are three types of fingerprint patterns: Arches, loops and whorls. Finger prints of both hands are not same and they persist throughout life unless there is damage to the dermis. The patterns of fingertip patterns begin to form around the 13th week of intrauterine life. These patterns are inherited in from genetic makeup of the parents but the inheritance is not purely Mendelian. They get modified during the first few weeks of the intrauterine life due to pressure on the finger pads and on the palms.
\end{abstract}

Key Words- Epidermal, Dermatoglyphics, Genetic, Arches.

\section{INTRODUCTION}

Dermatoglyphics (Greek word derma = "skin," glyph = "carving") is the scientific study of fingerprints. (Saumann and Alter, 1976; Kiran et al, 2010). Dermatoglyphics are of considerable importance in anthropology, criminology, medicine, chromosome abnormalities such as Trisomy 21 (Anitha et al, 2014). The study of fingerprints as a method of identification is also known as Dactylography or Dactyloscopy( Redomero et al, 2014.) and currently it is also known as the Henry-Galton system of identification. Dactylography is the process of taking the impressions of epidermal ridges of the fingertips for the purpose of identification of a person. Epidermal ridges and their arrangement exhibit a number of properties that reflect the biology of an individual. Finger print patterns are statistically different between the sexes, ethnic groups and age categories. As dermatoglyphics and their components are genetically determined and the arrangement of ridges remains constant throughout life, they have become of value as a supportive aid in the diagnosis of hereditary disorders (Crawford and Duggirala, 2014) Dermatoglyphic patterns appear during third never change in the life of an individual. Any abnormalities due to genetic or other factors express their effect before the end of fifth month of foetal development (Balirameshchaube, 1994). The Recent evidences have proved the basis for genetic contributions in diabetes mellitus and in various medical disorders. Hence dermatoglyphic variation is an essential investigation for its early diagnosis (Grey, 1918; Cummins and Midlo, 1961).

Fingerprints were taken from face cream which was spread on a kymograph paper. The paper was fixed in shellac after developing an impression with lamp black fine powder. It helps the subjects from inconvenience of staining of hands.( Macarthur and Ford, 1937). $X$ ray has an advantage of use in taking the fingerprints of decomposed bodies. $X$ ray records are used for the correlation of the position of triradii and hand skeleton by fastening lead pellets with adhesive at the point of the triradii.

Submitted $25^{\text {th }}$ October 2017. Published online $28^{\text {th }}$ February 2018. To cite: Sehmi S. Dermatoglyphic patterns in type 2 diabetes mellitus. Anatomy Journal of Africa. 2018. Vol 7 (1): $1162-1168$.

to fifth month of foetal life and once formed 
The ink method is the most widely used method in which a small amount of ink is spread over the slab with the roller into a thin even film. Fingertips and the palms are pressed against the paper placed over the rubber pad.

The ridge patterns on the distal phalanges of the fingertips are divided into the three types: arches, loops, and whorls (Hong and Jain, 1999). In normal individuals, the percentage of loops is $60-65 \%$, whorls are $30-35 \%$ and $5 \%$ are the arches. An order of prevalence of universal distribution for the ten fingers is as follows- Right hand (thumb to little finger): whorl - whorl - ulnar loop - whorl - ulnar loop Left hand (thumb to little finger): whorl - whorl - ulnar loop - whorl - ulnar loop (Mensvoort, 2013)

Arch- an Arch is formed by ridges lying one above the other in a general arching formation. The arch pattern is subdivided into two types a) Simple or plain arch composed of ridges that cross the fingertip from one side to the other without recurving; b) Tented arch composed of ridges that meet at a point so that their smooth sweep is interrupted(Maltani et al,2009).

Loop- A loop consists of one or more free re curving ridges and one delta. The loop pattern is subdivided into two types: a) Ulnar loop composed of ridges that open on the ulnar side and $b$ ) Radial loop composed of ridges that open on the radial side (Jain et al, 1999).

Whorl- Any fingerprint pattern which contains 2 or more deltas is known as whorl. There are four types of whorl patterns. a) Plain whorls consist of one or more ridges which make or tend to make a complete circuit with two deltas. b) Central pocket loop whorls consist of at least one re-curving ridge or an obstruction at right angles to the line of flow with two deltas between which when an imaginary line is drawn no re-curving ridge within the pattern area is cut or touched. c) Double loop whorls consist of two separate and distinct loop formations with two separate and distinct shoulders for each core, two deltas and one or more ridges forming a complete circuit d) Accidental whorl is a pattern which possesses some of the requirements for two or more different types or a pattern which conforms to none of the definitions (Issrani and Sinha, 2013).

The three basic dermatoglyphic patterns on palm are ri-radius- formed by the confluence of three ridge systems that form angles of approximately 120 degree with one another.Core- The approximate center of fingerprint pattern. Radiant-These are lines emanating from the tri-radius and enclose the pattern area (Sahauman and Alter, 1976; Durham and Plato, 1990).

In the distal part of the palm there are four triradii, one proximal to each finger except the thumb and are named $a, b$ c, $d$ from index to little finger respectively. At the proximal end of the palm in line with the middle finger, there is normally another triradius - the axial triradius $t$ and it is customary to record the widest 'atd' angle from the distal triradius. The atd angle is an indication of distal displacement of axial triradius. The 'atd' angle is measured by joining the digital tri radius ' $a$ ' to axial tri radius ' $t$ ' and to the digital tri radius'd.'. Also the atd angle tends to decrease with age because the palm grows more in length than in breadth. This problem can be partially overcome by introducing the age correction. The atd angle is also affected by the amount of spreading of fingers when the patterns are printed. The pressure exerted while the palm is printed also can affect the atd angle(Berg, 1968). The knowledge of this inter digital area ridge count is essential for the diabetologists treating diabetes mellitus.

\section{Embryology of fingerprints}

The development of epidermal ridges are preceded by the formation of volar pads that first appear as elevations on the palm around 6.5 weeks post fertilization followed by the five digits approximately one week later. Volar pads exhibit rapid growth between 6.5 and 10.5 weeks. Initially the pads appear evenly rounded; however by the 9th week, the pads begin to vary in both position and shape (Hanbi, 1991). Champod et al ( 2004) postulated that fingerprint patterns depend on the underlying arrangement of peripheral 
nerves whilst Fujimoto et al (2003) suggested that the ridges followed lines of greatest convexity in the embryonic epidermis.

\section{Indices used in dermatoglyphics}

The frequency distribution indices are unique fingerprint calculations that can be used to determine an individuals or a specific population distribution of patterns. These indices cannot be the same within different individuals hence forensic experts frequently used it to identify persons of interest. However these patterns can be used to determine the fingerprint distribution of one population to
another(Issrani and Sinha, 2013). These indices include: Pattern intensity index (PII): ( $2 \times \%$ whorl+\% loop) +10$)$; arch/whorl index of Dankmeijer"s; ( $\%$ arches $\div \%$ whorl) $\times 100$; and whorl/loop index of Furuhata"s; (\% whorl t\% of loop) $\times 100$. ${ }^{22,16}$ The highest 'pattern intensity index' in the world is found in Australia and Northern America with average 'pattern intensity index' above 15.5. The lowest 'pattern intensity index' in the world is found in central Africa with an average 'pattern index' below 10 (Mensvoort, 2013)

\section{Discussion}

\section{Arches}

Dermatoglyphic studies showed the prevalence of different dermatoglyphic patterns in different research studies. Panda et al (2004) showed increase in arches in diabetes in both sexes but Sant et al (1983) and Rezal et al (1999) showed increase in arches only in diabetic females than the control. No significant increase either in males or females was shown in study done by Rajaniganda et al (2006); Mandascue et al (2000); Nayak et al (2015); Umana et al (2013). Sharma and Sharma(2013) and Sachdev(2012) reported that the diabetics have significantly lower arches than controls. Both male and female diabetics showed a significant increase in frequency of loops and arches and a decreased frequency of whorls especially in middle finger. Bala et al (2015) showed significantly decreased number of arches in the right hand of male diabetics and left hand of female diabetics. $a-b$ ridge counts were higher in all the patients and statistically significant in diabetic females in right hands of males. Brute et al (2013) revealed that percentage of arches was more in diabetic males and females than in the controls and the difference observed in male group was not statistically significant. Study by Marera et al (2015) showed a significant increase of arch patterns among diabetic patients than in the control group. However some fingers such as the ring finger completely lacked an arch pattern in both groups. Study by Roshani et al (2016) and
Padmini et al (2011) showed more arches in females as compared to males in both right and left hands while Sengupta and Borush (1996) showed more arches in male diabetics.

\section{Radial Loop}

Ravindranath et al (1995), Panda et al (2004) found increase in radial loop in both sexes of diabetics. Bets et al91994) showed decrease in incidence of the radial loop in diabetics and Verbov et al (1973) ; Sant et al (1983); Rajnigandah et al (2006); Mandascue et al (2000); Nayak et al (2015) found no statistically significant difference in the radial loop pattern in diabetics and controls.

\section{Ulnar loop}

Panda et al (2004); Ravindranath et al (1995) showed increase in ulnar loop patterns in both sexes in diabetics but Sant et al (1983) showed decrease in ulnar loop in both sexes. Nayak et al (2015) showed no significant difference in the diabetics and control.

\section{Whorls}

Sant et al (1983) noticed significant increase in frequency of whorls in both sexes of diabetics but Ravindranath et al (1995) and Panda et al (2004) showed decrease in number of whorls in diabetics as compared to control. Rajnigandha et al (2006) and Mandascue et al (2000) showed no significant difference in the diabetics and controls. Study by Akshailekshmi and Anandaranl(2016) showed frequency of whorls was significantly more in diabetics and 
the frequency of ulnar loops and arches were significantly less in both hand of male and female cases. These findings are similar to the findings of Ferozhan et al (2003). Nassemabeegum(2013) observed that diabetics showed a significant increase in whorls than controls and arch patterns were found to be significantly decreased in diabetics when compared to controls Sengupta et al (1996) found that there was an increased frequency of whorls in male diabetics. Srivastava and Rajasekhar(2014) found that there was increase frequency of whorl pattern in both sexes. Ferozhan et al (2003) observed significantly increased in whorls and significantly decreased loops in diabetics. In study by Sachdev(2012) both male and female diabetics showed a significant increase in frequency of loops and arches and a decreased in the frequency of whorls especially in digit III i.e. Middle finger with PPV $=100 \%$ in right hand of females and left hand of males had chances of type 2 DM(Marera et al, 2015). In the study done by Roshani et al (2016) whorls were found most significantly common in both right and left hands of diabetic females which was similar to Khan et al (2009); Sant et al (1983); Sengupta et al (1996). This was dissimilar to the study by Karim et al (2014)(whorls were decreased while the loops were more); Ravindranath et al (1995) and Verbov et al (1973) which showed decreased number of the whorls in diabetics as compared to the controls.

\section{Atd angle}

Wider 'atd' angle and the additional axial triradii were seen as reliable indicators helpful in scientific screening of populations prone to diabetes mellitus. Rajnigandha et al (2006); Mittel and Lala(2013) ;Sharma et al (2013) ; Nayak et al (2015) showed increase in atd angle in both the sexes of diabetics while Mandascue et al (2000); Bala et al (2015); Srivastava and Rajasekhar(2014) gave decrease in the atd angle. Mandasescu et al (2000) showed right hand 'atd' angle was significantly lower in male diabetics only. Padmini et al (2011) showed increase in atd angle in male diabetics only. Verbov et al (1973) pointed out a decrease in $a-b$ ridge count in female IDDM patients. Similar findings were also reported by Zieglar et al (1993) There appear to be little agreement between the findings of various authors. Possible reasons are due to the small sample sizes chosen, incomplete diagnoses, control group inadequacy, statistical errors, and lack of openmindedness in subjects. To conclude, though dermatoglyphics generally do not play any major role in clinical diagnosis, it can serve as a ready screener to select individuals from a larger population for further investigations to confirm or rule out diabetes mellitus.

\section{Ridge count}

Bala et al (2015) showed higher mean a b ridge count in diabetics than control and highly significant in females. Similar findings were recorded by Ziegler et al (1993); Oladipo and Ogunnowo(2004) while Tarca(2006) found decrease in a b count in diabetics. A study done by Perumal and Manjunath(2016) showed statistically significant decreased levels of mean right $a-b$ and left $a-b$ ridge count were observed in male Type 2 diabetes mellitus patients compared to normal male subjects and also decreased levels of mean right b-c, left c- $d$ ridge counts in male Type 2 diabetes mellitus patients compared to normal male subjects but these values were statistically insignificant.

\section{CONCLUSION}

Dermatoglyphic investigation is absolutely cost effective and requires no hospitalization and it can help in predicting the phenotype of possible future illness. It can be used as a screening tool for early identification of at-risk individuals and prevent the further complications. Several studies done in different population have identified significant correlation between different fingerprint patterns and diabetes. However the type of pattern identified varies from one region to another. This may be because of racial dermatoglyphic differences from one population to the other. There are also different types of diabetes mellitus depending on their cause and each may present genetically with a different pattern. There appears to be little agreement between the 
findings of various authors. Possible reasons are due to the small sample sizes, incomplete diagnoses, control group inadequacy, statistical errors, and lack of open-mindedness in subjects. Though dermatoglyphics generally do not play any major role in clinical diagnosis, it can serve as a ready screener to select individuals from a larger population for further investigations to confirm or rule out diabetes mellitus.

\section{REFERENCES}

1. Akshailekshmi $P$, Anandarani VS. 2016. Dermatoglyphics of fingers and its clinical correlation with Type II diabetes mellitus. Internat J Sci Res. 5(3):195-6.

2. Anitha C, Konde S, Raj N, Kumar N, Peethamber P.2014. Dermatoglyphics: A genetic marker of early childhood caries. J Ind Soc of Pedodontics and Preventive Dentistry. 32(3): 220.

3. Bala A, Deswal A, Sarmah PC, Khandalwal B, Tamang BK.2015. Palmar dermatoglyphic patterns in diabetes mellitus and diabetic with hypertension patients in Gangtok region .Int J Adv Res. 3(4):1117-25.

4. Balirameshchaube RS.1994. Application and methodological perspectives in dermatoglyphics. Northern book center, New Delhi.

5. Berg JM.1968. The study of td dermal ridge count on the human palm. Hum Biol. 40: 375-85.

6. Bets LV, Dzhanibekova IV, Lebedev NB, Kuraeva TL.1994. Constitutional and dermatoglyphic characteristics of children with diabetes mellitus. Probl Endokrinol (Mosk). 40(1): 6-9.

7. Burute P, Kazi SN, Swamy V, Arole V.2013. Role of dermatoglyphic fingertip patterns in the prediction of maturity onset diabetes mellitus (type 2). IOSR-JDMS. 8(1):1-5

8. Champod C, Lennard CJ, Margot P, Stoilovic M. 2004. Fingerprints and other ridge skin impressions: CRC press.

9. Crawford M and Duggirala R. 2014. Digital Dermatoglyphic Patterns of Eskimo and Amerindian Populations: Relationships between Geographic, Dermatoglyphic, Genetic, and Linguistic Distances. Human biology. 64(5): 4.

10. Cummins $\mathrm{H}$ and Midlo C.1961. Finger Prints Palms and Soles: An Introduction to Dermatoglyphics. $1^{\text {st }}$ Ed. New York: Dover Publications. 272.

11. Durham, N.M. and Plato, C.C. eds., 1990. Trends in dermatoglyphic research (Vol. 1). Springer Science \& Business Media.

12. Fujimoto I, Yamada Y, Morizono T, Umetani, Y, Maeno T.2003. Development of artificial finger skin to detect incipient slip for realization of static friction sensation. Paper presented at the Multisensor Fusion and Integration for Intelligent Systems, MFI 2003. Proceedings of IEEE International Conference on.

13. Grey H.1918. Grey's Anatomy the anatomical basis of clinical practice. 4th edition. Lea publisher. England.

14. Hanbi G.1991. The Standard Items in the Study and Observation of Dermatoglyphics . Hereditas (Beijing). 1: 013.

15. Hong L and Jain A.1999. Classification of fingerprint images. Paper presented at the Proceedings of the Scandinavian Conference on Image Analysis.

16. Issrani N P R and Sinha SMGMS.2013. Dermatoglyphics in Health and Diseases-A Review.

17. Jain AK, Prabhakar S, Hong L.1999. A multichannel approach to fingerprint classification. Pattern Analysis and Machine Intelligence, IEEE Transactions on. 21(4):348-359.

18. Kahn HS, Graff M, Stein AD, Lumey LH. 2009. A fingerprint marker from early gestation associated with diabetes in middle age: The Dutch Hunger Winter Families Study. Int J Epidemiol. 38: 101-109.

19. Karim J, Mohammed AL, Saleem A.2014. Dermatoglyphic study of Finger Print Pattern's variations of a group of Type II Diabetes Mellitus Patients in Erbil City Zanco J Pure and Applied Sci.6(4):11. 
20. Kiran, Rai K, Hegde AM.2010. Dermatoglyphics as a noninvasive diagnostic tool in predicting mental retardation. J Inter Oral Health. 2(1):95-100.

21. Macarthur JW and Ford N.1937. A Biological study of the dionne quintuplets all Identical Set. Univ. Toronto Studies, Child Development Series, Univ. Toronto Press. 11: 49.

22. Maltoni D, Maio D, Jain AK, Prabhakar S.2009. Handbook of fingerprint recognition: Springer.

23. Mandasescu S. Richards B, Cadman J.1999. Detection of pre- diabetics by palmar prints: a computer study leading to a low cost tool. XIV International Congress of the Federation for Medical Informatics. Dec 31; Germany. Manchester; GMDS: 2000.

24. Marera DO, Oyieko W, Agumba G.2015. Variation in dematoglyphic patterns among diabetes in Western Uganda population. Afr J Sci Res. 3(7):20-25.

25. Mavalwala J and Hunt EE.1964. Finger and palm prints of the Micronesians of Yap. Zeitschrift für Morphologie und Anthropologie. 11-23.

26. Mittal M and Lala BS.2013. Dermatoglyphics: An economical tool for prediction of diabetes mellitus. Int J Med Health Sci. 2(3): 292-297.

27. Nayak V, Shrivastava U, Kumar S, Balkund K.2015. Dermatoglyphic study of diabetes mellitus Type 2 in Maharashtrian population. Inter J Medical Sci Res Prac. 2(2):66-69.

28. Oladipo $G$ and Ogunnowo BM.2004. Dermatoglyphic patterns in diabetes mellitus in a south eastern Nigerian population, Afr J Applied Zool Environ Bio. 6: 6-8.

29. Padmini MP, Rao BN, Malleswari.2011. The study of Dermatoglyphics in Diabetics of North Coastal Andhra Pradesh Population. I J Funda Appl Life Sci. 1(2):75-80.

30. Panda M, Chinara PK, Nayak AK.2004. Dermatoglyphics in diabetes mellitus. J Anat Soc India. 53:33-66.

31. Pathan F and Gosavi A.2011. Dermatoglyphics in type II diabetes mellitus. As quoted in www.journal.mimsr.edu.in.

32. Perumal A and Manjunath KY.2016. A study on inter digital area ridge count in type 2 diabetes mellitus. Int J Res Rev. 3(3):21-24.

33. Rajanigandha V. Mangala P, Latha P, Vasudha S.2006. Digito - Palmar complex in diabetes. Turk J Med Sci. 36:353-5.

34. Ravindranath R and Thomas IM.1995. Finger ridge count and finger print pattern in maturity onset diabetes mellitus. Indian Journal of Medical Science. 49 153-156.

35. Redomero EG, Rivaldería N, Rodríguez, CA, Andrés ÁS.2014. Assessment of the methodology for estimating ridge density in fingerprints and its forensic application. Science and Justice. 54(3): 199-207.

36. Rezal F, Haddad F, Shahri NM.1999. A Report of Dermatoglyphics Characteristic in a Barbarian Populations Resident in Khorasian Province and its Application in Physical Anthropology, A Collection of Paper Abstract, Iranian First Congress on Applied Biology. Mashhad, Iran. 164.

37. Roshani S, Amita S, Prabhakar S, Bezbaruah NK, Anshu M.2016. Dermatoglyphic Patterns among Type 2 Diabetic Adults In North Indian Population.Int J Curr Med Pharma.2(8); 609-61.1

38. Sachdev B.2012. Biometric screening method for predicting type 2 diabetes mellitus among select tribal population of Rajasthan. Int J Cur Bio Med Sci. 2(1): 191-194.

39. Sant SM, Vare AM, Fakhruddin S.1983. Dermatoglyphics in diabetes mellitus. J Anat Soc India 32:127-30.

40. Schaumann B and Alter M. 1976. Dermatoglyphics in medical disorders. New York: Springer Verlag. 1-129.

41. Sengupta $S$ and Borush J.1996. Finger dermatoglyphic patterns in diabetes mellitus. J Hum. Ecol. 7(3):203-206.

42. Sharma MK and Sharma H.2012. Dermatoglyphics: A Diagnostic tool to predict diabetes. J of Clinic Diag Res. 6(3):327-32.

43. Srivastava S and Rajasekhar S.2014. Comparison of digital and palmar dermatoglyphic patterns in diabetic and non-diabetic individuals. IOSR. 13(7):93-95.

44. Tarcă A.2006. Dermatoglyphics in diabetes mellitus of type 2 (T2DM) or non-insulin dependent.Journal of Preventive Medicine. 14(1-2): 60-70. 
45. Umana UE, Ronke R, Timbuak J, Ibegbu A, Musa SA, Ikyembe D, Hamman WO.2013. Dermatoglyphic and Cheiloscopic Patterns among Diabetic Patients: A Study in Ahmadu Bello University Teaching Hospital Zaria, Nigeria. J Bio Life Sci. 4(2), 206-214.

46. Verbov JL.1973. Dermatoglyphics in early onset diabetes mellitus. Human Heredity. 23, 535542.

47. Walker NF.1957. Inkless methods of finger, palm and sole printing. J Pediat. 50:27-29.

48. Ziegler AG, Mathies R, Mayer GZ, Baumgarti HJ, Rodewald A, Chopra V, Standl E.1993. Dermatoglyphics in type 1 diabetes mellitus. Diabet Med.10 (8):720-724. 